\title{
Rancang Bangun Alat Pendeteksi Tingkat Stress Pada Manusia Berbasis Arduino Uno
}

\author{
Nuril Hidayah \\ Politeknik Negeri Sriwijaya \\ Jln. Srijaya Negara, Bukit \\ Besar, Kec. Ilir Bar. I, Kota \\ Palembang, Sumatera \\ Selatan 30139 \\ nurilheer@yahoo.com
}

\author{
Martinus Mujur Rose \\ Politeknik Negeri Sriwijaya \\ Jln. Srijaya Negara, Bukit \\ Besar, Kec. Ilir Bar. I, Kota \\ Palembang, Sumatera \\ Selatan 30139 \\ mujurrose@yahoo.com
}

\author{
Nasron \\ Politeknik Negeri Sriwijaya \\ Jln. Srijaya Negara, Bukit \\ Besar, Kec. Ilir Bar. I, Kota \\ Palembang, Sumatera \\ Selatan 30139 \\ nasron6819@gmail.com
}

\begin{abstract}
Stress can be sourced from a variety of things, many negative impacts without us realizing that stress is caused by health. Therefore, a tool capable of being used to automatically measure stress levels in humans is required as a tool to monitor health. This human stress level detection tool uses a tool used to measure the level of human tension condition with three parameters, namely measuring heart rate using pulse sensor, body temperature using temperature sensor DS18B20 and skin moisture using galvanic skin response (gsr) sensor then the data will be sent, processed and processed using Arduino Uno R3 Microcontroller to process information to determine the level of stress condition of a person classified into 4 conditions namely relax, calm, anxious, and tense. Data retrieval is done for 1 minute with the measurement data results displayed on the LCD monitor screen.
\end{abstract}

Keywords : Heart Rate, Body Temperature, Skin Moisture, Stress, Arduino Uno, Pulse Sensor, GSR Sensor, Temperature Sensor DS18B20, LCD $20 x 4$.

\section{PENDAHULUAN}

Stres dapat bersumber dari berbagai hal. Tandatanda reaksi stres pada manusia meliputi reaksi fisik seperti tingginya denyut jantung, menurunnya suhu tubuh dan berkeringat dingin. Banyak dampak negatif tanpa kita sadari yang diakibatkan oleh stres bagi kesehatan, maka diperlukan suatu alat yang mampu digunakan untuk mengukur tingkat stres pada manusia secara otomatis dan praktis.

Pengukuran denyut jantung, suhu tubuh dan kelembapan kulit saat ini masih menggunakan peralatan yang belum terintegrasi sehingga kurang efektif dan efisien. Contohnya seperti thermometer dan stetoskop merupakan alat yang biasa digunakan oleh tenaga medis untuk mengukur suhu tubuh dan denyut jantung. Tetapi, alat-alat tersebut digunakan secara terpisah untuk memonitoring kondisi kesehatan manusia. Kemajuan teknologi dibidang elektronika dan telekomunikasi turut membantu dalam pengembangan merancang berbagai sistem contohnya sistem yang dapat mendeteksi tingkat kestressan pada manusia secara otomatis dengan handal. Salah satu perkembangan teknologi yang memudahkan manusia yaitu board berbasis Mikrokontroller Atmega 328 Arduino Uno yang memiliki beragam fungsi dan sensor-sensor yang dapat digunakan untuk mengukur besaran-besaran fisis seperti temperatur, denyut jantung dan sensor lainnya. Penelitian yang akan dilaksanakan bertujuan untuk mengembangkan sebuah sistem mencakup software dan hardware yang dapat membantu mendeteksi tingkat stres pada manusia dengan parameter denyut jantung, suhu tubuh dan kelembapan kulit yang terintegrasi dalam satu alat sehingga seseorang tersebut dapat melakukan pengecekkan serta pengendalian terhadap emosinya dan dapat memonitoring kondisi kesehatannya dengan alat yang dapat digunakan sehari-hari dengan nyaman dan praktis.

Terdapat beberapa penelitian tentang perancangan alat pendeteksi stress yang memiliki parameter pulse sensor untuk mendeteksi denyut jantung pada pembuluh darah arteri pada ujung jari, sensor suhu DS18B20 untuk mendeteksi temperatur pada tubuh dan GSR (Galvanic Skin Response) sensor yang dapat mengindera dan mengukur tingkat kelembapan pada permukaan kulit (moisture). Sistem yang akan dikembangkan ini menggunakan Mikrokontroler Arduino Uno R3 sebagai pusat pengendali utama ketiga sensor tersebut yang terhubung secara langsung ke sistem pendeteksi dan software Arduino IDE berperan untuk memprogram arduino dan mengolah data tersebut. 


\section{Rancang Bangun Alat Pendeteksi Tingkat Stress Pada Manusia Berbasis Arduino Uno}

\section{TEORI DASAR}

Jantung adalah organ yang berupa otot, berbentuk kerucut, berongga, dengan pangkal diatas dan puncaknya di bawah miring kesebelah kiri. Jantung terletak di dalam rongga dada diantara kedua paru-paru, dibelakang tulang dada, dan lebih menghadap ke kiri daripada ke kanan. Jantung berfungsi untuk memompa darah keseluruh tubuh melalui pembuluh darah.

Denyut jantung adalah jumlah denyutan jantung per satuan waktu, biasanya per menit. Denyut jantung didasarkan pada jumlah kontraksi ventrikel (bilik bawah jantung). Denyut jantung mungkin terlalu cepat (takikardia) atau terlalu lambat (bradikardia). Denyut nadi adalah denyutan arteri dari gelombang darah yang mengalir melalui pembuluh darah sebagai akibat dari denyutan jantung. Denyut nadi sering diambil di pergelangan tangan untuk memperkirakan denyut jantung.

Berdasarkan sumber bahwa kondisi kesehatan manusia menurut denyut jantungnya dikelompokkan dalam tiga kelompok, diantaranya:

1. Bradikardia adalah denyut jantung seseorang yang berada dibawah 60 denyutan per menit.

2. Denyut jantung manusia sehat sekitar 60-90 denyutan per menit.

3. Takikardia adalah denyut jantung seseorang yang berada diatas 100 denyutan per menit.

Bradikardia atau detak jantung yang lemah (di bawah $60 \mathrm{bpm}$ ) dapat menjadi pertanda dari masalah pada sistem jantung. Jantung yang berdetak sangat lambat tidak dapat memompa cukup darah untuk memenuhi kebutuhan tubuh. Sedangkan takikardia adalah kondisi jantung yang berdetak terlalu cepat. Pada orang dewasa, detak jantung cepat biasanya berkisar diatas 100 bpm. Gangguan ini bisa disebabkan oleh stress, alkohol, kafein, demam, atau merokok. Respon tubuh terhadap stres dapat berupa napas dan detak jantung menjadi cepat, otot menjadi kaku, dan tekanan darah meningkat.

Ketika darah dipompa keluar dari jantung pada arteri atau dikenal dengan pembuluh nadi teraba suatu gelombang denyut dan denyut ini dapat teraba pula pada tempat dimana pembuluh arteri melintas, misalnya arteri radialis yaitu disebelah depan pergelangan tangan dan ujung jari. Saat keadaan ini volume darah pada ujung jari bertambah atau menggumpal. Kemudian sebaliknya pada saat jantung tidak memompa darah volume darah pada ujung jari menjadi lebih kecil.
Denyut arteri dapat menjadi lebih cepat atau lebih lambat ketika seseorang sedang gelisah, hilang kesadaran atau koma, ada gangguan pada jantungnya atau menderita panas. Dengan meraba gelombang denyut arteri, dapat dihitung kecepatan jantung yang berbeda-beda karena dipengaruhi oleh aktivitas seseorang dan juga oleh makanan, umur, dan emosi

Dalam alat pengukuran kondisi detak jantung seseorang ini, untuk pembacaan denyut nadi per menit dengan memanfaatkan pulse sensor yang ditempelkan di ujung jari manusia, seperti pada uraian di atas ujung jari manusia merupakan salah satu tempat melintasnya pembuluh arteri atau nadi, ujung jari dipilih karena pemasangan pulse sensor lebih mudah.

Suhu tubuh atau temperatur tubuh adalah perbedaan antara jumlah panas yang diproduksi oleh proses tubuh dan jumlah panas yang hilang ke lingkungan luar. Temperatur tubuh manusia dapat diukur dengan menggunakan termometer. Temperatur tubuh manusia yang dapat dibagi beberapa standar penilaian temperatur, antara lain :

Normal $\left(36,5-37,5^{\circ} \mathrm{C}\right)$, hipertermi $\left(38-39^{\circ} \mathrm{C}\right)$ dan hipotermi $\left(33-36^{\circ} \mathrm{C}\right)$. Biasanya hipertermi dialami oleh seseorang yang sedang sakit, misalnya demam dan sakit ringan lainnya. Hipotermi sering dialami seseorang yang tinggal di daerah kutub yang udaranya lebih dingin. Tubuh manusia mempunyai temperatur yang konstan yaitu antara $36,5^{\circ}$ sampai $37,5^{\circ} \mathrm{C}$. Tempat yang biasa digunakan untuk mengukur temperatur tubuh manusia biasanya adalah di mulut, ketiak dan anus. Temperatur normal pada ketiak sekitar $37^{\circ} \mathrm{C}$. Sementara manusia normal mempunyai temperatur tubuh antara $36,5^{\circ} \mathrm{C}$ sampai $37,2^{\circ} \mathrm{C}$.

Dalam alat pengukur tingkat kesetressan seseorang ini, untuk mengukur temperatur tubuh manusia dengan memanfaatkan sensor temperatur DS18B20 yang ditempelkan di ketiak atau telapak tangan manusia, seperti pada uraian di atas, temperatur normal yaitu sekitar $36-37^{\circ}$ C. Sedangkan saat seseorang dalam keadaan cemas atau berada dibawah tekanan, temperatur/suhu tubuhnya menurun sekitar $33-35^{\circ} \mathrm{C}$.

Respon Kulit Galvanik atau Galvanic Skin Response (GSR) adalah perubahan psikologis pada kulit akibat dari perubahan aktivitas kelenjar keringat, dimana kelenjar keringat akan aktif bila tubuh berada dalam kondisi tertekan. GSR dapat digunakan sebagai indikator ukur stres dengan input sentuhan kulit sebagai obyek pengukuran 


\section{Rancang Bangun Alat Pendeteksi Tingkat Stress Pada Manusia Berbasis Arduino Uno}

stres. Kulit manusia menunjukkan berbagai bentuk fenomena bioelektrik khususnya pada daerah jarijari, telapak tangan dan telapak kaki. Hal ini disebabkan jumlah serabut syaraf sensory unit pada jaringan bawah kulit daerah jari-jari, telapak tangan dan kaki jauh lebih banyak dibandingkan pada organ-organ lain. Sehingga pada pengukuran bio sinyal galvanic skin response, elektoda pengukuran ditempatkan lebih baik melalui dua jari tangan.

Banyak detektor stress yang ada juga menerapkan GSR sensor sebagai sinyal input kelembapan kulit atau konduktansi kulit. Konduktansi kulit merupakan indikasi psikologis atau fisiologis gairah yang dikendalikan oleh sistem syaraf otonom. Konduktansi kulit, juga dikenal sebagai respon kulit galvanik (GSR) adalah metode pengukuran konduktansi listrik pada kulit, yang bervariasi dengan tingkat kelembabannya. Kelenjar keringat yang dikontrol oleh sistem saraf simpatik, sehingga saat emosi kuat, mengubah daya tahan listrik pada kulit. Konduktansi kulit digunakan sebagai indikasi gairah psikologis atau fisiologis. Ketika rangsangan eksternal atau internal terjadi yang mengubah tingkat stress atau perhatian dalam sejumlah sistem internal ada sesaat ketika kulit benar-benar menjadi lebih baik konduktor listrik. Jika cabang simpatik dari sistem saraf otonom sangat terangsang, maka aktivitas kelenjar keringat juga meningkat, hal ini menyebabkan meningkatkan konduktansi kulit, untuk mengamati hasil GSR dengan baik pekerjaan fisik ekstra harus dihindari seperti halnya berolah raga, serta suhu udara ruangan juga mempengarui kinerja sensor ini maka pengukuran alat ini dilakukan pada kondisi suhu ruangan normal.

Stres adalah keadaan ketika individu berada dalam situasi yang penuh tekanan atau ketika individu merasa tidak sanggup mengatasi tuntutan yang dihadapinya. Atkinson men definisikan stres sebagai suatu kondisi ketika individu dihadapkan pada peristiwa yang mereka anggap membahayakan ketentraman kondisi fisik dan psikologis mereka. Stres merupakan suatu dampak dari sebuah keadaan yang bersumber dari keadaan yang tidak biasa. Sumber stres merupakan segala hal yang bersifat memberikan tekanan. Yang menjadi faktor utama penyebab stres adalah kejadian baik maupun buruk, frustasi, konflik, tekanan, dan kondisi lingkungan.

Tanda-tanda reaksi stres manusia meliputi reaksi fisik, antara lain tingginya detak jantung (increased heart rate), naiknya tekanan darah (elevated blood pressure), dan berkeringat dingin (cold hand). Menurut Elizabeth Scott, stres meliputi empat kondisi, yaitu tegang ( $\mathrm{s}=$ stressed), cemas $(\mathrm{t}=$ tense $)$, tenang $(\mathrm{c}=$ calm $)$, dan rileks $(\mathrm{r}=$ relaxed). Banyak dampak negatif yang diakibatkan oleh stres bagi kesehatan, maka diperlukan suatu alat yang mampu digunakan untuk mengukur tingkat stres pada manusia.

Stres adalah suatu kondisi ketegangan yang mempengaruhi emosi, proses berpikir dan kondisi seseorang. Orang-orang yang mengalami stress menjadi nervous atau cemas dan merasakan kekhawatiran kronis. Mereka sering menjadi marah- marah, agresif, tidak dapat rileks.

Seseorang mengalami stress dapat dilihat dari tanda-tanda, diantaranya adalah :

1. Gejala fisik : sakit kepala, tekanan darah naik, dan serangan jantung.

2. Gejala psikologis : sulit tidur, mimpi buruk, depresi, kerja gelisah, bingung, mudah tersinggung dan gejala depresi lainnya.

3. Gejala perilaku : membolos, uring-uringan, produktivitas menurun, dan sering membuat kekeliruan atau kesalahan kerja.

Arduino adalah kit elektronik atau papan rangkaian elektronik open source yang berukuran standar, lengkap terdapat komponen utama yaitu board berbasis chip microcontroller Atmega 328 dari perusahaan Atmel yang mempunyai kelebihan yang sama fungsional dengan Arduino jenis apapun. Board ini memiliki 14 digital input output pin (dimana 6 pin dapat digunakan sebagai output PWM), 6 input analog, 16MHz oscillator kristal, koneksi USB, jack listrik dan tombol reset. Pin-pin ini berisi semua yang diperlukan untuk mendukung microcontroller, hanya dengan menghubungkan nya ke komputer dengan kabel USB atau sumber tegangan yang bisa didapat dari adaptor AC-DC atau baterai untuk menggunakannya.

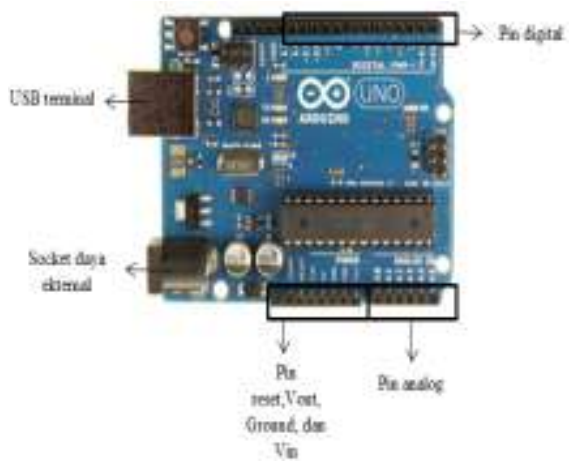

Gambar 1. Board Arduino Uno R3 


\section{Rancang Bangun Alat Pendeteksi Tingkat Stress Pada Manusia Berbasis Arduino Uno}

Sensor suhu DS18B20 merupakan suatu komponen elektronika yang dapat mengukur perubahan temperatur lingkungan kemudian mengkonversinya menjadi tegangan listrik. Sensor ini merupakan sensor dengan keluaran digital yang menggunakan 1 wire untuk berkomunikasi dengan microcontroller. Keunikan dari sensor ini adalah tiap sensor memiliki kode serial yang memungkinkan untuk penggunaan DS18B20 lebih dari satu dalam satu komunikasi 1 wire.

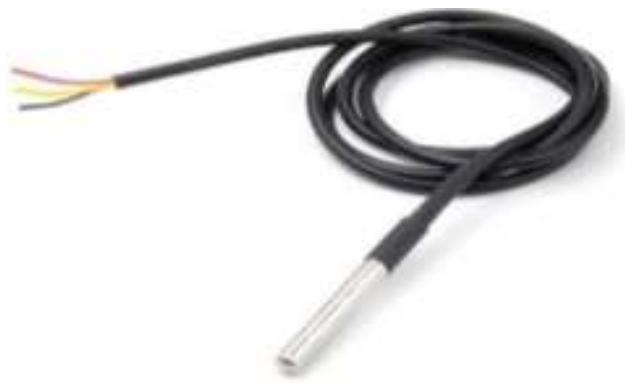

Gambar 2. Sensor suhu DS18B20

Pulse Sensor pada dasarnya adalah alat medis yang berfungsi untuk memantau kondisi denyut jantung pasien. Rangkaian dasar dari sensor ini dibangun menggunakan phototransistor dan LED. Sensor ini bekerja berdasarkan prinsip pantulan sinar LED. Kulit dipakai sebagai permukaan reflektif untuk sinar LED. Kepadatan darah pada kulit akan mempengaruhi reflektifitas sinar LED. Aksi pemompaan jantung meng akibatkan kepadatan darah meningkat. Pada saat jantung memompa darah, maka darah akan mengalir melalui pembuluh arteri dari yang besar hingga kecil seperti di ujung jari. Saat volume darah pada ujung dari bertambah maka intensitas cahaya yang mengenai phototransistor akan kecil karena terhalang oleh volume darah, begitu pula sebaliknya. Keluaran sinyal dari phototransistor kemudian dikuatkan oleh sebuah Op-Amp sehingga dapat dibaca oleh ADC mikrokontroler.

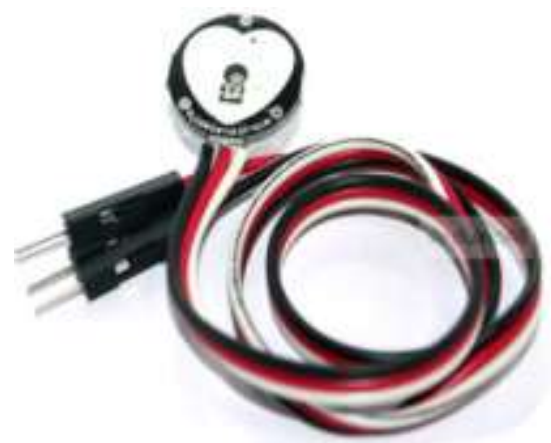

Gambar 3. Pulse sensor atau sensor detak jantung
Galvanic Skin Response (GSR) adalah sensor yang bisa mengindera dan mengukur tingkat konduktivitas (kemampuan suatu bahan menghantarkan listrik) dari kulit yang mana berbeda-beda tergantung tingkat kelembapan kulit (moisture) maupun kadar garam yang terdapat di keringat pada permukaan kulit. Hal yang menarik adalah bahwa dasarnya kelenjar keringat dipengaruhi oleh saraf simpatik dengan demikian berubahnya tingkat emosional seseorang akan mempengaruhi kelenjar keringat pada permukaan kulit dalam mensekresi keringat sehingga berdampak akhir pada peningkatan konduktivitas kulit. Dengan cara kerja demikian, sensor ini dapat digunakan dalam menentukan tingkat psikologis dan fisiologis manusia.

Ada beberapa tempat yang sangat layak untuk mengukur respon konduktansi kulit karena adanya kelenjar keringat eccrine (memproduksi keringat bening dan tidak berbau) yang sangat responsif terhadap rangsangan emosional dan psikologis. Telapak tangan dan telapak kaki memiliki tingkat tinggi kelenjar keringat eccrine sehingga elektroda biasanya ditempatkan pada kulit di daerah- daerah tertentu.

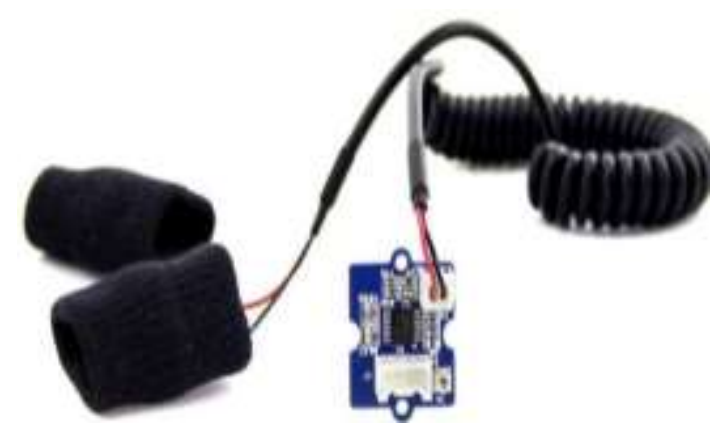

Gambar 4. Galvanic Skin Response (GSR) Sensor

Liquid Cristal Display (LCD) adalah kompo nen yang dapat menampilkan tulisan. LCD berfungsi sebagai penampil data baik dalam bentuk karakter, huruf, angka ataupun grafik. Maksud dari $20 \times 4$ adalah lcd ini memiliki 20 kolom/karakter dan 4 baris berbeda dengan lcd $16 \times 2$ yang hanya 16 kolom dan 2 baris. Tentunya dengan lcd $20 \times 4$ ini kita bisa menampilkan lebih banyak karakternya. Agar terhubung dengan Arduino lebih mudah jika menggunakan tambahan modul yaitu i2C backpack. I2C LCD Backpack Module mempunyai 16 pin output yang bisa dihubungkan dengan pin LCD 20x4 secara langsung (disolder permanen) dan memiliki 4 pin input (VCC, GND, SDA, SCL). 


\section{Rancang Bangun Alat Pendeteksi Tingkat Stress Pada Manusia Berbasis Arduino Uno}

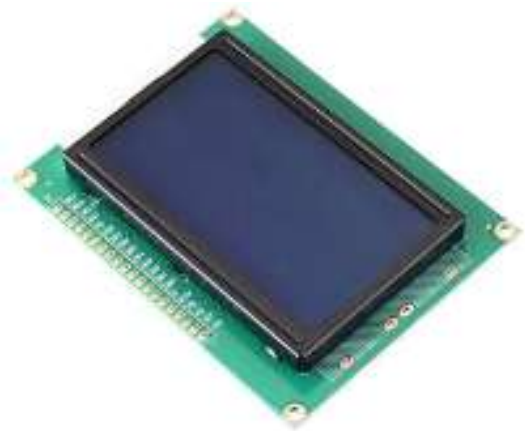

Gambar 5. Modul LCD 20x4

Buzzer adalah sebuah komponen elektronika yang berfungsi untuk mengubah getaran listrik menjadi getaran suara. Pada dasarnya prinsip kerja buzzer hampir sama dengan loud speaker, jadi buzzer juga terdiri dari kumparan yang terpasang pada diafragma dan kemudian kumparan tersebut dialiri arus sehingga menjadi elektromagnet, kumparan tadi akan tertarik ke dalam atau keluar, tergantung dari arah arus dan polaritas magnetnya.

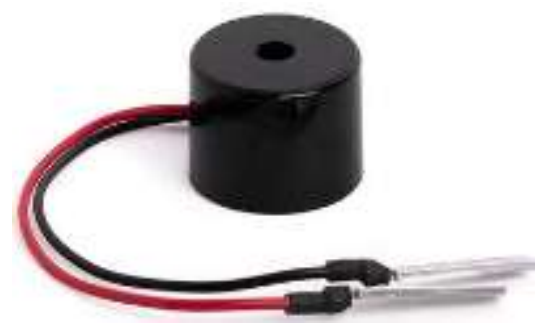

Gambar 6. Buzzer

Push Button adalah saklar yang berupa tombol dan berfungsi sebagai pemutus atau penyambung arus listrik dari sumber arus ke beban listrik. Suatu sistem saklar tekan push button terdiri dari saklar tekan start, reset dan saklar tekan untuk emergency. Push button memiliki kontak NC (normally close) dan NO (normally open).

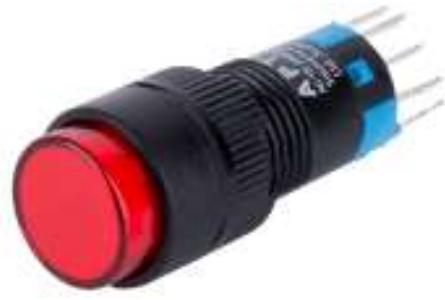

Gambar 7. Push Button

Adaptor merupakan sebuah perangkat berupa rangkaian elektronika untuk mengubah tegangan listrik yang besar menjadi tegangan listrik lebih kecil, atau rangkaian untuk mengubah arus bolakbalik (arus AC) menjadi arus searah (arus DC). Adaptor/power supply merupakan komponen inti dari peralatan elektronik. Adaptor digunakan untuk menurunkan tegangan AC 22 Volt menjadi kecil antara 3 volt sampai 12 volt sesuai kebutuhan alat elektronik.

Adaptor merupakan sebuah alternatif pengganti dari tegangan DC seperti baterai dan aki karena penggunaan tegangan $\mathrm{AC}$ lebih lama dan setiap orang dapat menggunakannya asalkan ada aliran listrik di tempat tersebut. Adaptor juga banyak di gunakan dalam alat sebagai catu daya, layaknya amplifier, radio, pesawat televisi mini dan perangkat elektronik lainnya.

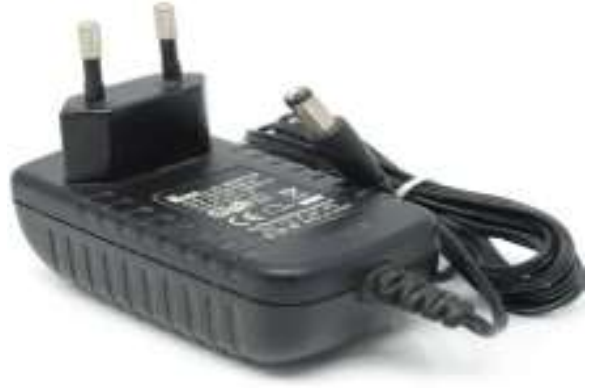

Gambar 8. Adaptor

\section{METODE PENELITIAN}

Penelitian ini dimulai dengan studi pustaka, mencari studi literature, metode cyber yaitu metode dengan cara mencari data yang ada kaitannya dengan masalah yang dibahas dari internet sebagai bahan referensi laporan serta metode perancangan adalah metode perancangan alat yang akan dibuat dan disesuaikan dengan kehidupan sehari-hari.

Pada perancangan ini terdapat beberapa komponen utama yaitu Adaptor sebagai catudaya, Mikrokontroller Arduino Uno sebagai bagian utama dari sistem, Pulse Sensor, Sensor suhu DS18B20 dan GSR sensor Dan berikut ini merupakan blok diagram dari sistem pendeteksi tingkat stres yang telah dirancang :

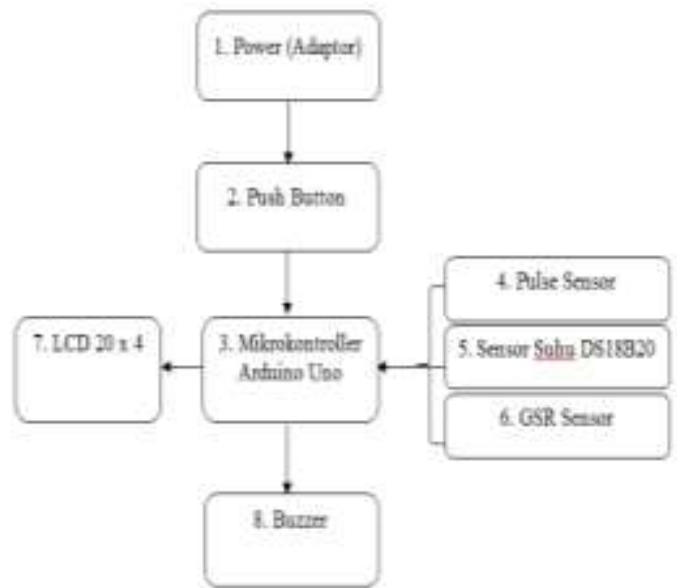

Gambar 9. Diagram Blok Alat Pendeteksi Tingkat Stres Pada Manusia 


\section{Rancang Bangun Alat Pendeteksi Tingkat Stress Pada Manusia Berbasis Arduino Uno}

Keterangan Blok Diagram :

1. Adaptor/catu daya berfungsi sebagai daya input yang digunakan untuk LCD, Mikrokontroler arduino uno, Pulse sensor, Sensor Suhu DS18B20, Galvanic Skin Response (GSR) Sensor dengan tegangan sebesar $12 \mathrm{~V}$.

2. Push button berfungsi sebagai pemutus atau penyambung arus listrik dan digunakan untuk tombol.

3. Mikrokontroller Arduino Uno merupakan bagian utama dari sistem yang berfungsi untuk mengolah input untuk diproses kemudian memberikan perintah ke output dan memproses keseluruhan data yang diberikan oleh komputer.

4. Pulse sensor berfungsi untuk memantau kondisi denyut jantung pada jari.

5. Sensor suhu DS18B20 berfungsi untuk memantau temperatur pada tubuh.

6. GSR sensor berfungsi untuk memantau tingkat kelembapan kulit pada kepadatan kelenjar keringat tertinggi pada kulit.

7. LCD $20 \times 4$ berfungsi untuk menampilkan data informasi tentang status alat dan menampilkan keterangan hasil percobaan.

8. Buzzer berfungsi sebagai bunyi indikator pada saat menggunakan alat.

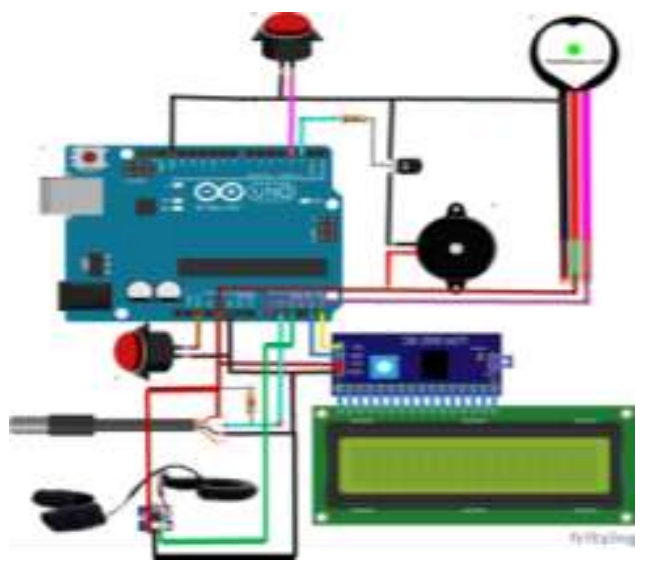

Gambar 10. Skema Rangkaian Keseluruhan Rancang Bangun Alat Pendeteksi Tingkat Stress Pada Manusia Berbasis Arduino Uno

Sistem pendeteksi stress ini menggunakan tiga buah sensor yaitu Pulse Sensor, Sensor Suhu DS18B20 dan Galvanic Skin Response Sensor sebagai pembacaan kondisi tubuh pada manusia yaitu mendeteksi denyut jantung pada jari, temperatur atau suhu tubuh dan kelembapan pada kulit. Keluaran ketiga sensor tersebut akan dikirim dan diolah oleh mikrokontroler arduino uno. Selanjutnya Mikrokontroler Arduino Uno berfungsi sebagai pusat pengolah data dan pengendali ketiga sensor tersebut yang telah terprogram pada software Arduino IDE. Kemudian LCD 20x4 akan menampilkan informasi di layar sebagai penampil data hasil dari ketiga sensor tersebut dan secara otomatis buzzer akan berbunyi yang merupakan pertanda bahwa sensor telah mendeteksi kulit dan menerima data yang telah tampil pada layar LCD. Setelah itu sistem akan otomatis reset kembali. Pada rangkaian ini menggunakan adaptor sebagai perantara untuk mengantar tegangan listrik sebesar $12 \mathrm{~V}$.

\section{HASIL DAN PEMBAHASAN}

Pengujian perbandingan pada Pulse Sensor ini dilakukan untuk mengetahui seberapa efektif pembacaan yang dilakukan alat yang telah dirancang dengan alat yang sudah ada di rumah sakit yaitu Elektrokardiografi (EKG) jenis ECG100G.

\section{Pengujian dan Perbandingan Pulse Sensor}

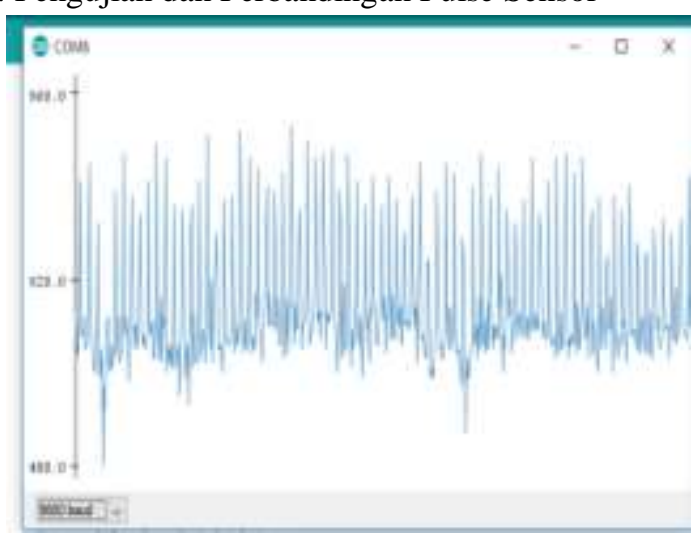

Gambar 11. Tampilan pulse sensor dalam kondisi on pada serial monitor.

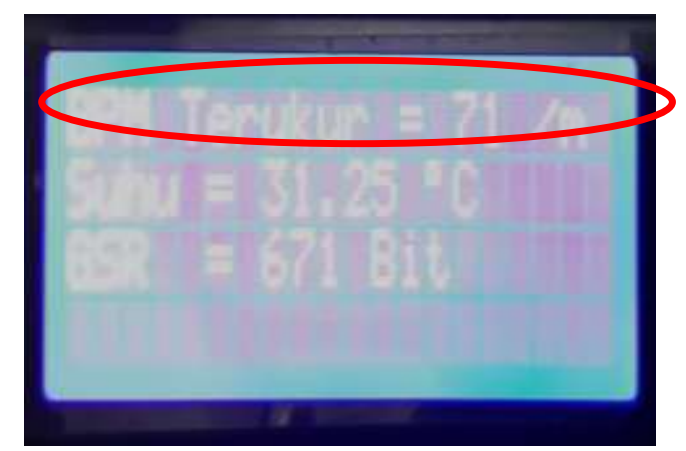

Gambar 12. Hasil pengujian Pulse Sensor pada monitor LCD. 


\section{Rancang Bangun Alat Pendeteksi Tingkat Stress Pada Manusia Berbasis Arduino Uno}

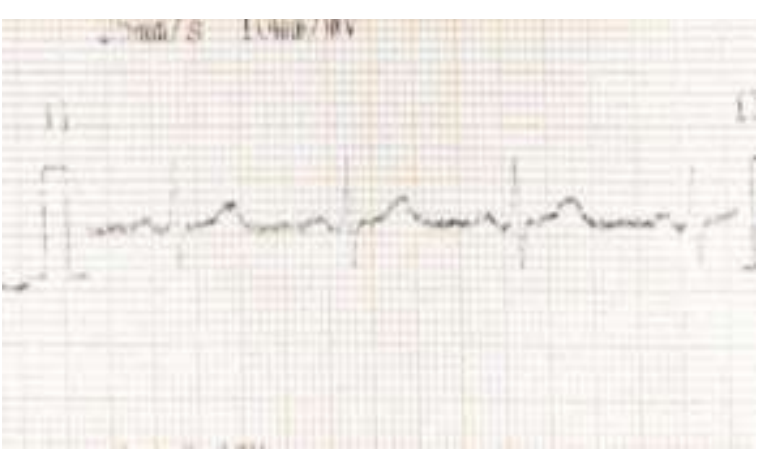

Gambar 13. Hasil Rekam Jantung dengan Alat

Rekam Jantung Elektrokardiografi (EKG).

Pengujian ini bertujuan untuk mengetahui seberapa persen keakuratan pulse sensor yang dibandingkan dengan alat rekam jantung EKG.

Dari pengujian yang diambil, menunjukkan hasil pengukuran dari EKG untuk detak jantung hasilnya 75 bit/menit, sedangkan pada pulse sensor menunjukkan hasil sebesar $71 \mathrm{bit} /$ menit. Dengan demikian dapat diperoleh tingkat akurasi dari pulse sensor yang dibuat sebesar $96,8 \%$.

2. Pengujian dan Perbandingan Sensor Suhu DS18B20

Pengujian perbandingan pada Sensor Suhu DS18B20 ini dilakukan untuk mengetahui seberapa efektif pembacaan yang dilakukan alat yang telah dirancang dengan alat yang sudah ada yaitu Termometer digital. Pengukuran menggunakan termometer digital dilakukan selama +1 menit hingga mencapai titik kestabilan pengukuran yang ditandai dengan bunyi beep. Pengukuran menggunakan sensor suhu DS18B20 juga dilakukan selama 1 menit.

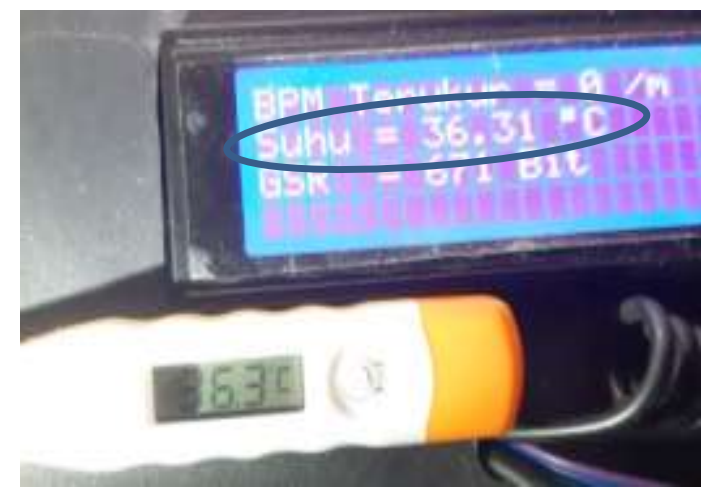

Gambar 14. Pengujian Sensor Suhu DS18B20 dan Termometer Digital

Pengujian Sensor Suhu DS18B20 ini dilakukan untuk mengetahui seberapa efektif pembacaan yang dilakukan alat yang telah dirancang dengan alat yang sudah ada yaitu Termometer digital. Berdasarkan pengujian diatas dapat disimpulkan bahwa sensor suhu DB18B20 mempunyai rata-rata tingkat error sebesar $0,31 \%$. Dengan demikian dapat diperoleh tingkat akurasi dari sensor suhu DS18B20 yaitu sebesar $99.69 \%$.

\section{Pengambilan Data}

Untuk pengambilan data perancangan alat pendeteksi tingkat stress pada manusia ini yaitu mengambil suatu sampel denyut jantung, suhu tubuh dan kelembapan kulit pada jari yang akan ditest dengan alat yang telah dirancang. Dan pada hasil yang akan diidentifikasi kondisinya ada 4 tingkat yaitu kondisi rileks, tenang, cemas dan tegang (stres).

Namun sebelum memasuki pengambilan data, ada hal yang perlu diketahui tentang pengelompokkan kondisi seseorang sebagai berikut

Tabel 1. Pengelompokkan Kondisi Tingkat Stres

\begin{tabular}{|c|c|c|c|c|c|}
\hline GSR (tit) & $\mathrm{I}_{\mathrm{f}(\mathrm{C})}^{\mathrm{HR}(\mathrm{Gra})}$ & $\begin{array}{l}\text { I4IBAI } \\
\text { (5I) }\end{array}$ & $\begin{array}{c}\text { CtKIP (Et } \\
x)\end{array}$ & $\begin{array}{l}\text { B.IIK } \\
\text { 01-9h }\end{array}$ & IINGG ( $\gg 1)$ \\
\hline \multirow{3}{*}{$\begin{array}{l}\text { YORJLAL } \\
k=3 W 6)\end{array}$} & NOPBCAI (36.3I) & RIIFXS & RIIEKS & RILEKS & REEXS \\
\hline & AGAKR DENGN (63-35) & RMEKS & IENANG & IENAXG & CEMAS \\
\hline & DINGLX(G3) & RHIEKS & IENANG & CEMAS & CEMAS \\
\hline \multirow{3}{*}{$\begin{array}{l}\text { CUNJP } \\
\text { (901-525) }\end{array}$} & NOBSLAI [36-3I) & RIIEKS & IENAXG & IENANG & IENANG \\
\hline & AGAS DLNGN ( 33.35$)$ & IENANG & IENANG & IENANG & CEMLAS \\
\hline & DNGD (G3) & IENAXG & IENANG & CEMAS & CEMAS \\
\hline \multirow{3}{*}{$\begin{array}{l}\text { AGAR } \\
\text { TNGGI } \\
(526-62 \mathrm{n})\end{array}$} & NOBSLAI (36-3I) & RHEKS & IEXANG & CEMAS & CEMAS \\
\hline & AGAR DIVGN (53-35) & IENANG & IENANG & CEMAS & CEMASS \\
\hline & DNGEN (Gi) & CEMLAS & CEMAAS & CEMAS & CEMAS \\
\hline \multirow{3}{*}{$\begin{array}{l}\text { INGGI } \\
\text { (6)1611) }\end{array}$} & NOBULAI (36-3I) & RHFKS & TENANG & CEMLAS & CEMALS \\
\hline & AGAR DINGIX (33-35) & TENAXG & IENANG & CEMAS & TEGANG \\
\hline & DNGEN(G3) & IENAXG & CEMLAS & CEMAS & TEGANG \\
\hline
\end{tabular}

Lalu, tingkat kondisi diatas telah diinput pada pemograman sehingga untuk hasil keluaran tingkat stres telah didapatkan akan sesuai dengan kondisi denyut jantung, suhu tubuh dan kelembapan pada kulit. Berikut ini merupakan beberapa hasil pengambilan data pada 10 subjek yang sudah dilakukan dari uji coba Alat Pendeteksi Tingkat Stres Pada Manusia yang telah dirancang.

Berikut ini merupakan hasil pengujian dan pengambilan data. Salah satu pengambilan data ini dilakukan pada subjek Elsa, Umur 21 tahun : 


\section{Rancang Bangun Alat Pendeteksi Tingkat Stress Pada Manusia Berbasis Arduino Uno}

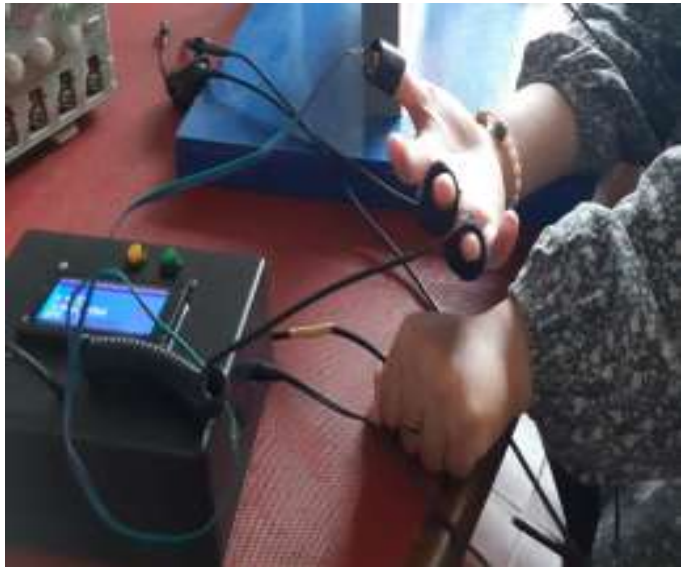

Gambar 15. Proses Pengambilan Data

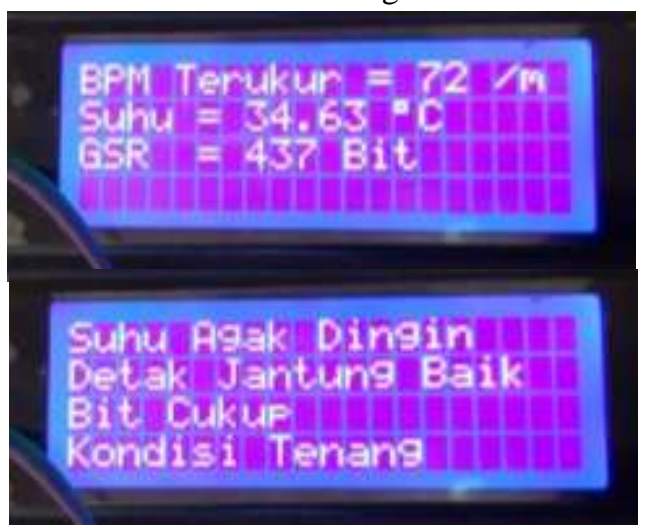

Gambar 16. Hasil Pengujian Alat Pendeteksi Tingkat Stres

Gambar 16 diatas merupakan salah satu hasil pengujian sistem secara keseluruhan yang menunjukkan bahwa pengukuran tingkat stres yang dilakukan pada subjek pertama menghasilkan nilai detak jantung 72 bpm (detak jantung baik), suhu tubuh 34.63 0C (suhu tubuh agak dingin), kelembapan kulit 437 bit (bit cukup) dan kondisi tubuh tenang.

Tabel 2. Hasil Pengambilan Data Tingkat Stres Pada Subjek

\begin{tabular}{|c|c|c|c|c|c|c|}
\hline $\begin{array}{c}\text { Subjeks } \\
\text { ke- }\end{array}$ & Nama & Usia & $\begin{array}{c}\text { Detak } \\
\text { Jantung } \\
\text { (bpm) }\end{array}$ & $\begin{array}{l}\text { Suln } \\
\text { Tubuh } \\
\text { (C) }\end{array}$ & GSR (bit) & $\begin{array}{l}\text { Kondisi } \\
\text { Tubuh }\end{array}$ \\
\hline $\mathrm{t}$ & Elsa & 21 tabu & 72 & 34.63 & 437 & Tenang \\
\hline 2 & Nisa & 15 talum & 93 & 37.25 & 408 & Teuang \\
\hline 3 & Rizki & 10 tahm & 98 & 37.06 & 256 & Rileks \\
\hline 4 & Syifa & 13 tahm & 96 & 36.63 & 651 & Cemas \\
\hline 5 & Rangga & 21 tahm & 75 & 35.63 & 488 & Tenang \\
\hline 6 & Arli & 21 tabu & 72 & 36.25 & 576 & Rilekss \\
\hline 7 & Ade & 21 tabm & 82 & 36.19 & 457 & Tenang \\
\hline 8 & Farah & 21 tahm & 70 & 36.88 & 660 & Tenang \\
\hline 9 & Kartina & 20 tahm & 82 & 36.94 & 651 & Cemas \\
\hline 10 & Dina & 21 tahu & 77 & 35.13 & 439 & Tenang \\
\hline
\end{tabular}

Untuk melakukan pengujian tingkat stres ini ada baiknya pada bagian kulit pada jari dibersihkan terlebih dahulu agar tidak kotor dan basah yang dapat mempengaruhi kinerja sensor, tidak melakukan aktivitas fisik yang berat dan diuji pada suhu ruangan normal untuk mendapatkan hasil keluaran kondisi yang akurat.

Rancang bangun alat pendeteksi tingkat stres pada manusia berbasis arduino uno ini menggunakan input daya dari adaptor dengan spesifikasi tegangan 12 VDC dan arus 1 A. Cara kerja sistem pendeteksi ini yaitu dengan cara menempelkan jari pada pulse sensor, memasukkan dua jari ke elektroda gsr sensor dan menggenggam sensor suhu DS18B20, lalu menekan tombol start warna kuning dan sensor akan mulai mengirim data jari ke Arduino Uno dan membaca sensor selama 1 menit. Setelah dikirim oleh ketiga sensor dan diterima oleh Arduino Uno, Maka Arduino Uno akan membaca denyut jantung, suhu tubuh, dan kelembapan pada kulit dan mengolah data apakah sesuai dengan data yang sudah terdaftar didalam program. Setelah hasil pembacaan Arduino Uno, data akan ditampilkan pada layar LCD. Tampilan pada LCD ini berupa proses pengukuran, sinyal yang terukur pada pulse sensor, dan $\mathrm{n}$ atau timer selama 1 menit. Setelah itu LCD akan menampilkan jumlah denyut nadi (bpm), suhu tubuh $\left({ }^{0} \mathrm{C}\right)$, kelembapan tubuh (bit), dan kondisi tubuh pada subjek yang melakukan pengukuran pada alat.

Berdasarkan data yang telah didapatkan, maka dapat diketahui bahwa untuk menentukan tingkat kondisi stress pada seseorang, buat terlebih dahulu pengelompokkan kondisi denyut jantung, suhu tubuh dan kelembapan pada kulit terlebih dahulu agar didapatkan 4 tingkat kondisi yaitu rileks, tenang, cemas dan tegang. Setelah itu, lakukan pengujian sebanyak kurang lebih 2 sampai 5 kali pada subjek yang sama untuk mendapatkan hasil yang lebih akurat.

Berdasarkan hasil pengujian terhadap 10 subjek pada tabel 1 , diperoleh data bahwa terdapat 2 subjek dengan kondisi rileks, 6 subjek dengan kondisi tenang dan 2 subjek dengan kondisi cemas. Kondisi subjek yang terdeteksi cemas yaitu denyut jantung yang tinggi, suhu tubuh normal dan kelembapan kulit yang tinggi. Penting untuk diingat, kondisi tingkat stres seseorang dapat berubah seiring dengan kondisi pikiran, mental, kegiatan, usia dan lingkungan yang mempengaruhi kondisi fisik pada subjek. Dari pengujian sistem 


\section{Rancang Bangun Alat Pendeteksi Tingkat Stress Pada Manusia Berbasis Arduino Uno}

secara keseluruhan tersebut dapat disimpulkan bahwa sistem telah dapat berjalan dengan baik dalam pengukuran tingkat kondisi stres pada manusia.

\section{KESIMPULAN}

Berdasarkan hasil penelitian dan analisis data yang didapatkan, maka dapat disimpulkan sebagai berikut yaitu Rancang bangun alat pendeteksi tingkat stress pada manusia berbasis arduino uno ini dirancang dengan menggunakan Pulse Sensor sebagai pendeteksi denyut jantung pada ujung jari yang ditempelkan pada jari telunjuk atau ibu jari, Sensor Suhu DS18B20 sebagai pendeteksi temperatur/suhu tubuh pada telapak tangan, Galvanic Skin Response (GSR) Sensor sebagai pendeteksi kelembapan kulit pada jari yang elektrodanya ditempelkan pada jari tengah dan jari manis. Data ketiga parameter tersebut diolah dan diproses oleh Mikrokontroller Arduino Uno R3 yang berperan sebagai pusat kendali utama sistem yang terhubung secara langsung ke sistem pendeteksi. Pengambilan data dilakukan selama 1 menit ditampilkan pada layar monitor LCD matrix 20x4 yang hasil akhir untuk setiap kondisi telah diklasifikasikan sebagai : rileks, tenang, cemas, dan tegang. Berdasarkan hasil yang diperoleh, tingkat keberhasilan akurasi pulse sensor dalam mendeteksi detak jantung sebesar 96,8\%, hasil yang diperoleh tersebut merupakan perbandingan dengan Elektrokardiografi (EKG) jenis ECG-100G. Sedangkan tingkat keberhasilan akurasi sensor suhu DS18B20 dalam mendeteksi suhu tubuh sebesar 99,69\%, hasil tersebut merupakan perbandingan dengan termometer digital merek General Care. Pengukuran suhu tubuh menggunakan sensor DS18B20 memiliki tingkat keakuratan yang sangat baik dengan rata-rata error hanya sebesar $0,31 \%$. Sedangkan pada pengukuran denyut jantung menggunakan pulse sensor, tingkat keakuratannya cukup baik namun error yang dihasilkan rata-rata sebesar 3,2\%. Faktor-faktor yang dapat mempengaruhi hasil pengukuran denyut jantung tersebut diantaranya adalah peletakkan sensor pada jari yang kurang sesuai, jari yang terlalu basah atau sinyal denyut yang lemah serta lengan harus rileks pada saat pengukuran. Secara keseluruhan sistem dapat berjalan dengan baik dalam pengukuran tingkat stres dan alat yang digunakan dapat berjalan sesuai yang diharapkan. Berdasarkan hasil pengujian pengambilan data terhadap 10 subjek, diperoleh data bahwa terdapat
2 subjek dengan kondisi rileks, 6 subjek dengan kondisi tenang dan 2 subjek dengan kondisi cemas. Kondisi subjek yang terdeteksi cemas yaitu denyut jantung yang tinggi, suhu tubuh normal dan kelembapan kulit yang tinggi. Dari pengujian sistem secara keseluruhan tersebut dapat disimpulkan bahwa kinerja alat pendeteksi ini telah dapat bekerja dengan baik dalam pengukuran tingkat kondisi stres pada manusia.

\section{DAFTAR PUSTAKA}

[1] Suryani, Tatik dan Widyantoro. 2011. Analisis Faktor-Faktor Yang Mempengaruhi Tingkat Stres Kerja Pada Tenaga Edukatif Tetap Perguruan Tinggi Swasta.

[2] Noer Muhammad Hedi Pratama. 2018. Rancang Bangun Deteksi Stress Pada Sistem Pemantau Kesehatan Manusia Berbasis Arduino Nano. Jurusan Teknik Elektro, Fakultas Teknik, Universitas Lampung.

[4] Kresna Hadya, Pradhipta. 2014. Rancang Bangun Alat Pengukur Tingkat Stres Menggunakan Metode Fuzzy Logic. Program Studi S1 Sistem Komputer, Jurusan Sistem Komputer, Sekolah Tinggi Manajemen Informatika \& Teknik Komputer Surabaya.

[5] Utomo, Satryo Budi dan Bambang Supeno. 2016. Rancang Bangun Alat Ukur Kondisi Kesehatan Pada Pendaki Gunung Berbasis Fuzzy Logic. Jember : Fakultas Teknik Universitas Jember. 